\title{
Vegetable and fruit consumption and its determinants in young Finnish adults
}

\author{
By Tea Lallukka, Marjaana Lahti-Koski and Marja-Leena Ovaskainen \\ Received: February 12, 2001; Revised: May 21, August 22, 2001; Accepted: September 4, 2001
}

\begin{abstract}
Background: The low consumption of vegetables and fruit among young adults is a growing universal concern.

Objective: To examine determinants of vegetable consumption among young Finnish adults aged 25 to 34 years.

Design: A questionnaire covering health behaviour, socio-economic status and food frequencies was sent to subjects in 1997 (participation rate 64\%, $\mathrm{n}=1589$ ). A 24-h recall was collected for a subsample of these participants.

Results: Education, parental status, place of midday meal, perception of diet, physical activity, and smoking explained $21 \%$ of habitual use of vegetables and fruit in women aged $25-29,29 \%$ in women aged $30-34$ and $25 \%$ in men of both age groups. Frequent consumption of vegetables and fruit was associated with a higher vegetable and fruit intake in the 24-h recall.

Conclusion: Effective strategies to increase consumption of vegetables and fruit are needed. Particularly young adults with low education, smokers or the physically inactive are at high risk for inadequate vegetables and fruit in their diets.

Key words: Education, Finland, lifestyle, vegetable consumption, young adults
\end{abstract}

\section{Introduction}

According to dietary recommendations, diets should be based on vegetables, roots, fruit, berries and cereal products (1). The increased consumption of vegetables and fruit has been the most prevalent change in food patterns of Northern Europeans $(2,3)$. However, young adults and adolescents seem to have a low consumption of vegetables and fruit (4-7).

While numerous studies exist on the regular diets of adolescents, studies concerning young adults (aged 25-34 years) are scarce. Nevertheless, young adults are in many ways an interesting group for examining food choices. Parental influence can have a strong impact on the development and persistence of health beliefs and behaviours (8). However, dietary choices may be modified for many reasons during early adulthood and may be overshadowed by other life aspects, leading to an unsatisfactory $\operatorname{diet}(9)$.

The low nutrient density in the diet of young adults is one of the main dietary concerns in Finland (10). While the intake of potatoes, roots, and fruit and berries has been found to be lower in the youngest age group (25-34 years) compared with older adults (35-64 years), the intake of fresh vegetables appears not to vary across these age groups (11). However, a high density of fat and sugar and a low density of fibre has been found to be associated with low fruit and vegetable intake among young Danish women (12).

Associations between high education and more frequent consumption of vegetables and fruit seem convincing (13-16). In addition, lifestyle factors, such as non-smoking $(5,15,17)$ and physical activity (18), have been found to correlate positively with vegetable and fruit consumption. Attention to a healthy diet also seems to be an important predictor of healthy food choices $(4,19)$.

Tea Lallukka, MSc*, Marjaana Lahti-Koski, MSc, Marja-Leena Ovaskainen $\mathrm{PhD}$, National Public Health Institute, Dept of Epidemiology and Health Promotion, Unit of Nutrition, Mannerheimintie 166, FIN-00300 Helsinki, Finland.

Correspondence: Marja-Leena Ovaskainen

E-mail: marja-leena.ovaskainen@ktl.fi
The objective of this study was to examine associations of consumption of vegetables and fruit with socio-economic and lifestyle factors among young Finnish adults. A further aim was to identify strategies for health specialists to promote healthy food choices in young adults.

\section{Subjects and methods \\ Study design}

The data used in this study were collected as part of the FINRISK study, which was carried out to assess the levels of cardiovascular risk factors in Finland between January and March 1997 (20). For the FINRISK study, a random sample of 10000 persons aged 25-64 years was drawn from the population registers of five regions: the cities of Helsinki and Vantaa (capital region), the cities of Turku and Loimaa and their surrounding rural communities, and the provinces of Oulu, Kuopio and Northern Karelia. In each region and ten-year age group, the sample included 250 men and 250 women. The subjects were invited to a health examination at a local health centre. The participation rate was $72 \%(\mathrm{n}=7159)$.

Along with the invitation to the local health centre, a questionnaire to be completed at home was sent to subjects. This included questions on health, food choices and education as well as on marital, parental and employment status. In addition, a 38-item food frequency section was included. Information on subjects' weight and height was obtained by measurements carried out at the health centre. This study reports data on the youngest age group (25-34 years) only. Participants comprised 725 men and 864 women, the overall participation rate being $64 \%$ (58\% for men and $69 \%$ for women).

At the examination, $40 \%$ of participants (1016 subjects) were invited to further participate in a more extensive dietary interview. In all, 305 men and 361 women (participation rate $66 \%$ ) completed the dietary survey. In the 1997 dietary survey, participants were interviewed by the 24 -h recall method and $99 \%$ of the recalls were accepted $(n=666)$. To control for measurement error, three-day food diaries $(n=73)$ and repeated $24-\mathrm{h}$ recalls $(n=59)$ were collected (11). 


\section{Variables}

An aggregated variable of consumption of vegetables and fruit Nas constructed from five original food items on the food requency questionnaire (FFQ) of the FINRISK 1997 Study. subjects were asked to specify using six alternatives how often hey had eaten vegetables and fruit during the past 12 months Table 1). A sum index of frequencies of vegetable and fruit consumption was calculated using questions on frequencies of resh vegetables, root crops, fresh salads, cooked vegetables, regetable dishes, fruit and berries. Potatoes were not included in he aggregate. The original responses were converted into numser of consumptions per month $(0,1.5,4.5,9,25$ and 35 times/ nonth). Following this modification, subjects were categorized nto two groups based on the sum index: vegetable and fruit sonsumption of either $<60$ (low) or $\geq 60$ (high) times per month. Educational level was divided into two groups: low (12 years it most) and high (more than 12 years) education. Parental status was defined as either having children of 16 years or younger or tot having children. Occupation was originally divided into seven categories: farmer, blue-collar worker, white-collar worzer, student, housewife, pensioner or unemployed. In this study, our groups were used after combining the four latter groups.

The midday meal on weekdays was originally allocated to one of six categories. These alternatives were combined in our study o describe either a self-made lunch (packed lunch or lunch at 1ome) or a lunch prepared by someone else (at a restaurant, bar, worksite canteen or other cafeteria). Subjects who had lunch in tn unspecified place or not at all formed a third, separate group. In lifestyle variables, participants were asked to describe their eisure-time physical activity (low, medium, high), perception of sersonal diet (healthy-unhealthy) and use of tobacco (smokerion-smoker).

\section{Statistical analyses}

Statistical analyses were done using SAS programs. Variance analyses using the general linear model (GLM) procedure were serformed to estimate determinants of aggregated vegetable and fruit consumption. We formed a model to study factors that may ave an influence on vegetable and fruit consumption. Aggregated vegetable and fruit consumption (times per month) was the dependent variable. Parental status, educational level, lifestyle factors (perception of diet, physical activity, smoking habits) and midday meal were included as independent variables. The final model included all the variables mentioned above and it was adjusted for body mass index (BMI). Generalization of the GLM procedure, a mixed model for measurement error, was used to compare the means of food intake based on 24$h$ recalls of the subjects with low and high vegetable use according to the food frequency questionnaire.

Sexes were kept separate in all analyses. The ten-year age group was analysed as one group except in modelling, where it was divided into two 5-year age groups (25-29 years and 30-34 years). This was done because the socio-economic situation (marital and parental status, educational level, employment status) of participants varied with age, which could have caused bias in the analyses of variance when comparing the group means of ten-year age groups.

\section{Results}

Basic characteristics of study variables are shown in Table 2. About $69 \%$ of women and $53 \%$ of men had received an education of more than 12 years. Most of the subjects were married or cohabiting. About half of the women and $37 \%$ of men had children aged 16 years or younger. The majority of subjects who had children were married.
Table 1. Food frequency questionnaire (FFQ): How often do you usually consume following food items? Think over the latest 12 months. Answer every line. Circle the number that corresponds to frequency. The six alternatives were: 1 . Less than once/month or not at all //2. Once or twice/ month // 3. Once a week // 4. Twice a week // 5. Almost every day // 6. Once a day or more often.

\section{Vegetables}

Fresh vegetables, root crops or fresh salads Cooked vegetables Vegetable dishes

$\begin{array}{lllllll} & 1 & 2 & 3 & 4 & 5 & 6 \\ & 1 & 2 & 3 & 4 & 5 & 6 \\ & 2 & 3 & 4 & 5 & 6 \\ & & & & & & \\ & 1 & 2 & 3 & 4 & 5 & 6 \\ & 1 & 2 & 3 & 4 & 5 & 6\end{array}$

Table 2. Distribution (\%) of educational level, marital, parental and employment status, and occupation for young adults aged 25-34 years in the National FINRISK 1997 Study.

\begin{tabular}{|c|c|c|c|c|}
\hline \multirow{4}{*}{ Variable } & \multicolumn{2}{|c|}{ Men } & \multicolumn{2}{|c|}{ Women } \\
\hline & $\begin{array}{l}\text { INRISK } \\
1997\end{array}$ & 24-h recall & $\begin{array}{c}\text { FINRISK } \\
1997\end{array}$ & 24-h recall \\
\hline & $\mathrm{n}=725$ & $n=305$ & $\mathrm{n}=864$ & $n=361$ \\
\hline & $\%$ & $\%$ & $\%$ & $\%$ \\
\hline \multicolumn{5}{|l|}{ Educational level } \\
\hline 12 years or less & 47 & 50 & 31 & 33 \\
\hline over 12 years & 53 & 50 & 69 & 67 \\
\hline \multicolumn{5}{|l|}{ Marital status } \\
\hline married & 33 & 36 & 43 & 40 \\
\hline cohabiting & 30 & 29 & 30 & 33 \\
\hline single & 34 & 32 & 24 & 23 \\
\hline $\begin{array}{l}\text { separated, divorced } \\
\text { or widowed }\end{array}$ & 2 & 3 & 4 & 4 \\
\hline \multicolumn{5}{|l|}{ Parental status } \\
\hline no children & 63 & 60 & 45 & 46 \\
\hline children $\leq 16$ years & 37 & 40 & 55 & 54 \\
\hline \multicolumn{5}{|l|}{ Employment status } \\
\hline full-time job or student & 72 & 71 & 56 & 57 \\
\hline part-time job & 2 & 1 & 2 & 2 \\
\hline $\begin{array}{l}\text { unemployment } \\
\text { is imminent }\end{array}$ & 6 & 8 & 10 & 11 \\
\hline $\begin{array}{l}\text { unemployed, laid off, } \\
\text { maternity leave/retired }\end{array}$ & 20 & 20 & 32 & 31 \\
\hline \multicolumn{5}{|l|}{ Occupation } \\
\hline farmer & 8 & 8 & 4 & 4 \\
\hline blue-collar worker & 26 & 29 & 3 & 3 \\
\hline white-collar worker & 40 & 38 & 54 & 55 \\
\hline student & 12 & 9 & 14 & 15 \\
\hline housewife & 1 & 1 & 14 & 16 \\
\hline unemployed or pensioner & 13 & 15 & 10 & 8 \\
\hline \multicolumn{5}{|l|}{ Body mass index (BMI) } \\
\hline$\leq 25 \mathrm{~kg} / \mathrm{m}^{2}$ & 52 & 57 & 71 & 70 \\
\hline$>25 \mathrm{~kg} / \mathrm{m}^{2}$ & 48 & 43 & 29 & 30 \\
\hline
\end{tabular}


Table 3. Frequencies, times per month, mean (SD), of vegetable and fruit consumption ${ }^{\mathrm{a}}$ by socio-economic factors and diet perception of young adults in two age groups in the National FINRISK 1997 Study.

\begin{tabular}{|c|c|c|c|c|}
\hline \multirow[b]{2}{*}{ Variable $^{b}$} & \multicolumn{2}{|c|}{$\operatorname{Men}(n=725)$} & \multicolumn{2}{|c|}{ Women $(n=864)$} \\
\hline & $\begin{array}{c}25-29 \text { yrs. } \\
\mathrm{n}=343\end{array}$ & $\begin{array}{c}30-34 \text { yrs. } \\
\mathrm{n}=382\end{array}$ & $\begin{array}{c}25-29 \text { yrs. } \\
\mathrm{n}=402\end{array}$ & $\begin{array}{c}30-34 \text { yrs. } \\
n=462\end{array}$ \\
\hline \multicolumn{5}{|l|}{ Educational level } \\
\hline$\leq 12$ years & $33(27)$ & $41(29)$ & $58(34)$ & $57(31)$ \\
\hline$>12$ years & $48(29)$ & $51(27)$ & $66(32)$ & $72(32)$ \\
\hline Overall p-value & 0.008 & $\mathrm{~ns}$ & ns & 0.002 \\
\hline \multicolumn{5}{|l|}{ Parental status } \\
\hline no children & $42(28)$ & $45(28)$ & $67(33)$ & $66(31)$ \\
\hline children $\leq 16$ years & $39(32)$ & $48(28)$ & $60(32)$ & $67(33)$ \\
\hline Overall $\mathrm{p}$-value & $\mathrm{ns}$ & 0.02 & ns & $\mathrm{ns}$ \\
\hline \multicolumn{5}{|l|}{ Leisure-time physical activity } \\
\hline low & $30(27)$ & $37(26)$ & $53(30)$ & $54(28)$ \\
\hline medium & $42(32)$ & $49(28)$ & $65(34)$ & $69(32)$ \\
\hline high & $47(26)$ & $54(27)$ & $71(31)$ & $75(32)$ \\
\hline Overall p-value & 0.02 & 0.0004 & 0.02 & 0.004 \\
\hline \multicolumn{5}{|l|}{ Smoking habits } \\
\hline non-smoker & $47(30)$ & $51(29)$ & $68(32)$ & $70(32)$ \\
\hline ex-smoker ${ }^{\mathrm{c}}$ & $34(21)$ & $48(26)$ & $68(32)$ & $67(30)$ \\
\hline ex-smoker ${ }^{\mathrm{d}}$ & $57(37)$ & $43(23)$ & $75(43)$ & $73(45)$ \\
\hline smoker & $35(27)$ & $39(26)$ & $53(32)$ & $57(32)$ \\
\hline Overall p-value & 0.04 & $\mathrm{~ns}$ & 0.048 & ns \\
\hline \multicolumn{5}{|l|}{ Lunch } \\
\hline worksite cafeteria, & $50(28)$ & $55(24)$ & $72(29)$ & $77(29)$ \\
\hline at home or packed lunch & $36(30)$ & $44(29)$ & $61(34)$ & $64(32)$ \\
\hline no lunch or other & $30(22)$ & $36(27)$ & $61(37)$ & $49(32)$ \\
\hline Overall p-value & 0.0005 & 0.02 & $\mathrm{~ns}$ & 0.03 \\
\hline \multicolumn{5}{|l|}{ Perception of personal diet } \\
\hline healthy & $65(41)$ & $71(39)$ & $94(44)$ & $103(35)$ \\
\hline fairly healthy & $48(29)$ & $53(26)$ & $69(30)$ & $73(30)$ \\
\hline $\begin{array}{l}\text { not particularly healthy } \\
\text { or unhealthy }\end{array}$ & $34(25)$ & $38(25)$ & $50(28)$ & $51(26)$ \\
\hline (fairly) unhealthy & $23(24)$ & $23(15)$ & $50(25)$ & $41(26)$ \\
\hline Overall p-value & 0.0001 & 0.0001 & 0.0001 & 0.0001 \\
\hline R-Square & 0.25 & 0.25 & 0.21 & 0.29 \\
\hline
\end{tabular}

\footnotetext{
aimes per month, mean values, standard deviations in parentheses, includes fresh and cooked vegetables, vegetable dishes, fruit and berries; ${ }^{b}$ Adjusted for Body Mass Index and all variables presented in the model; ${ }^{c}$ finished smoking over a half year ago); ${ }^{d}$ finished smoking less than a half year ago; ns=non-significant (statistical test by GLM).
}

Of the men, $70 \%$ had full-time jobs or studied and $20 \%$ were temporarily or permanently unemployed. The corresponding proportions for women were $56 \%$ and $32 \%$. Nearly half of the men and one-third of the women were overweight (BMI>25).

\section{Socio-economic and lifestyle}

\section{factors explain vegetable consumption}

Young adults (aged 25-34 years), especially men, had lower consumption frequencies (p-value $\left(\mathrm{chi}^{2}\right)$ 0.001) of vegetables and fruit compared with older participants (aged 35-64 years) of the FINRISK study population (data not shown). Among the young adults, average consumption frequencies of vegetables and fruit were 44 and 65 times/month, for men and women, respectively.

Education, parental status, leisure-time physical activity, smoking habits, place of midday meal and perception of diet explained about $21 \%$ of the variation in aggregated vegetable and fruit consumption among women aged 25 to 29 and $30 \%$ among women aged 30 to 34 . For men in both 5-year age groups, the model explained $25 \%$ of the variation in the aggregated vegetable and fruit consumption (Table 3 ). For both men and women, the frequencies of consumption seemed higher for those with high education. These differences were significant for the younger 5-year age group in men and the older 5-year age group in women.

Non-smoking, lunch outside the home, high leisure-time physical activity and perception of having a healthy diet were also associated with higher frequencies of aggregated vegetable and fruit consumption. Only physical activity and perception of diet were significantly associated with aggregated vegetable and fruit consumption in all age groups. Parental status was also representative of marital status because most of the participants with children were married or cohabiting. However, having children or living with someone did not seem to have an impact on vegetable consumption, except for men aged 30 to 34 years. Having children seemed to be linked with their higher consumption of vegetables and fruit.

We also tested interaction between education and the midday meal, but the interaction was not statistically significant (data not shown). Adding occupation to the model had no affect on other results, so it was not included in the final model. Interactions between the midday meal and occupation and between education 


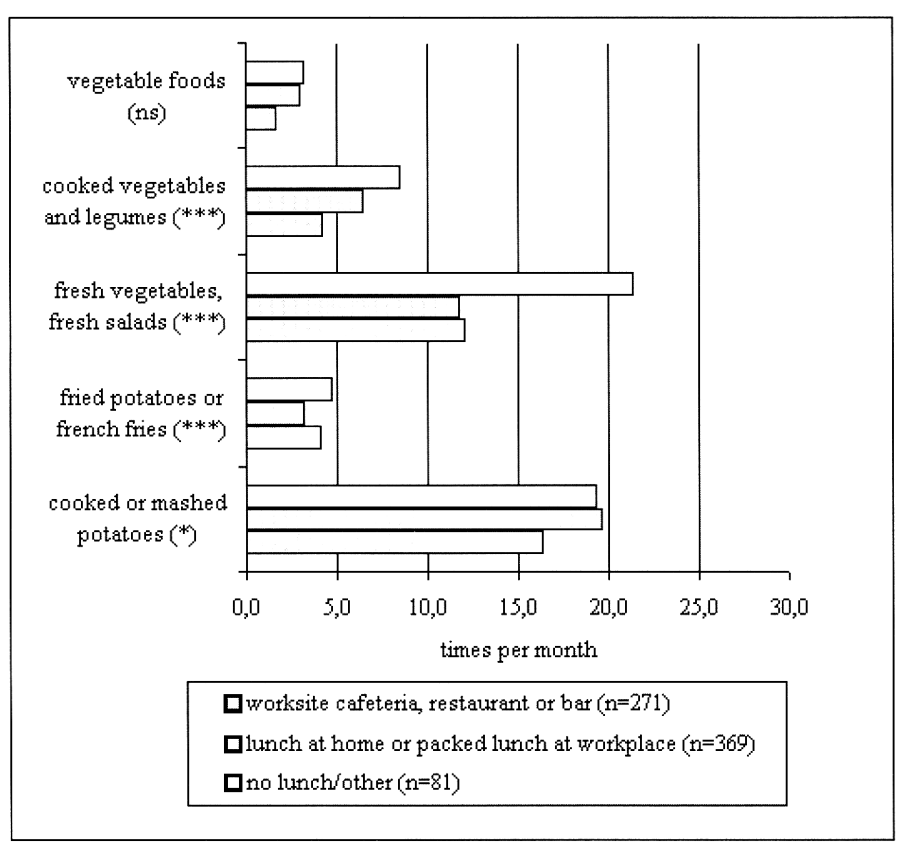

Figure 1. Frequencies for vegetable consumption (per month) by midday meal on weekdays for men aged 25-34 years in the FINRISK 1997 Study (tested by variance analysis:

$*$ p-value $<0.05 ; * *$ p-value $<0.01 ; * * *$ p-value $<0.001$; ns=non-significant)

and occupation were also analysed, but they were not statistically significant (data not shown).

Young women who frequently ate fast food had a lower consumption of vegetables and fruit than women who seldom ate fast food (data not shown). In contrast, no associations were found between alcohol intake and vegetable consumption.

The place of midday meal was clearly associated with consumption of separate vegetable groups (Figures 1 and 2). Those having lunch in a worksite cafeteria, restaurant or bar significantly more often consumed fresh and cooked vegetables than those having a homemade lunch or not eating lunch at all. Women who usually skipped lunch ate fried potatoes and french fries more frequently than women who ate lunch. In both education categories, the consumption of fresh vegetables or other vegetables was higher when lunch was usually eaten outside the home (data not shown).

\section{Vegetable and fruit intake by $24-h$ recall}

The high consumption of vegetables, fruit and berries according to the FFQ was combined with the higher fruit and fresh vegetable intake in the 24 -h recall (Table 4). Bread intake did not differ by vegetable intake for women, but the intake of rye bread was higher in the 24-h recall for men with more frequent vegetable consumption. For women, the intake of breakfast cereals and porridge was higher when they had had high frequencies of vegetable consumption according to the questionnaire. Frequency of eating french fries and fried potatoes was inversely associated with the frequency of vegetable and fruit consumption in women ( $p$-value 0.03 , data not shown) but not in men.

\section{Discussion}

Consumption of vegetables and fruit among young Finnish adults is lower than recommended. However, women seem to consume vegetables and fruit more often than men. High education, physical activity at leisure time, perception of healthy diet, non-smoking and eating lunch outside the home are associated with higher consumption of vegetables and fruit.

Education and occupation have been used as variables to study

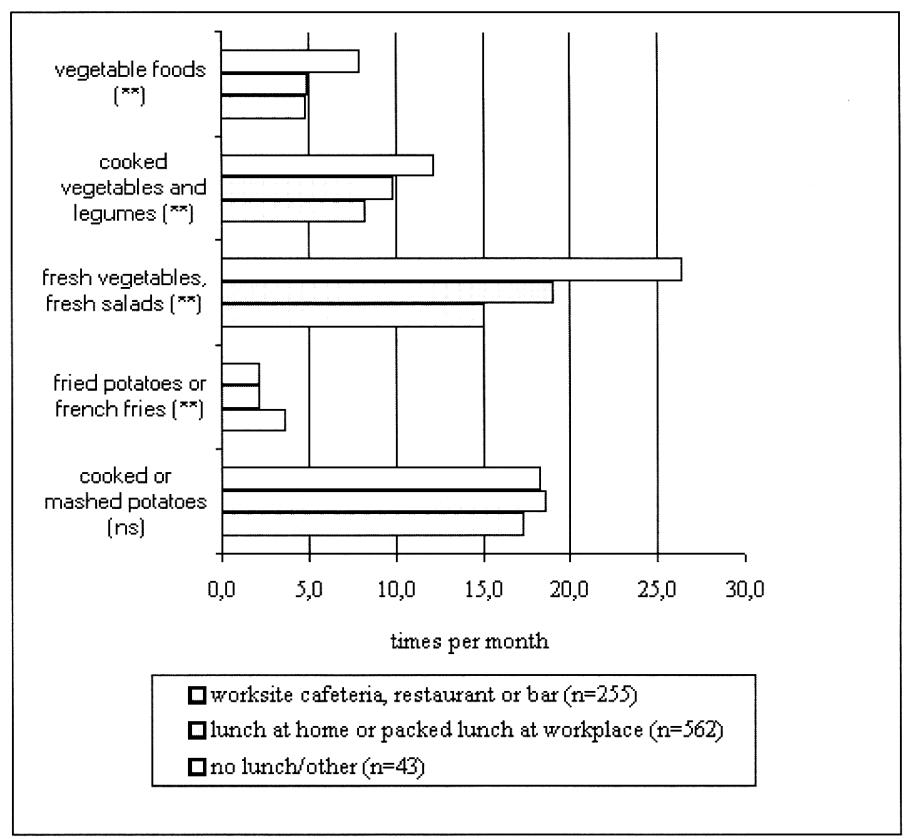

Figure 2. Frequencies for vegetable consumption (per month) by midday meal on weekdays for women aged 25-34 years in the FINRISK 1997 Study (tested by variance analysis:

$*$ p-value $<0.05 ; * *$ p-value $<0.01 ; * * *$ p-value $<0.001 ;$ ns=non-significant)

the impact of socio-economic status on vegetable consumption. A large meta-analyses covering 15 European countries using these indicators found that both higher level of education and occupation are associated positively with the consumption of vegetables and fruit (16). However, in our study, only high education was found to be associated with frequent consumption of vegetables and fruit. The lack of association between occupation and vegetable and fruit consumption might be partly explained by the young age and a lack of stable occupation of the participants and the abundance of students and housewives. Our finding that consumption of vegetables and fruit is higher for persons with high education is supported by earlier studies on adults in Finland (13) and Norway (4). Only $7 \%$ of Norwegian men and $13 \%$ of women with high education reached the US recommendation of vegetable consumption at least five times a day.

Persons with high education presumably have an increased ability to obtain or understand health-related information in general and the dietary information specifically needed to develop health-promoting behaviours (16). Such an interpretation of our results would suggest that strategies to increase consumption of vegetables and fruit, particularly among men with low education, are needed. Advertising and information campaigns aimed directly at this group might be one way to increase interest in eating more vegetables and fruit. However, economic status may also have had an impact on the higher vegetable and fruit consumption of participants with high education.

Subjects having lunch in a restaurant, bar or worksite cafeteria had a higher consumption of vegetables, especially fresh vegetables and salads. Educational level appears to be connected with eating in organized worksite cafeterias or the habit of having lunch in a restaurant. This was also suggested by our data, although the interaction between education and lunch place was not statistically significant. The social acceptability of vegetables and encouragement within the social network to choose vegetables or fruit may be different for persons with high education. In a worksite nutrition intervention (25), enabling and mediating factors were found to explain changes in dietary habits. On the other hand, participants with low education in our study also had a higher consumption of vegetables if they 
Table 4. Mean intake of vegetarian and cereal foods by $24-\mathrm{h}$ recall in low and high $^{\mathrm{a}}$ habitual consumers of vegetables and fruit $^{\mathrm{b}}$ (FFQ) in the National FINRISK 1997 Study.

\begin{tabular}{|c|c|c|c|c|c|c|}
\hline \multirow[b]{3}{*}{ Food by $24-\mathrm{h}$ recall } & \multicolumn{3}{|c|}{$\operatorname{Men}(n=305)$} & \multicolumn{3}{|c|}{ Women $(n=361)$} \\
\hline & \multicolumn{6}{|c|}{ Habitual vegetable and fruit consumption on FFQ } \\
\hline & $\begin{array}{l}\text { Low } \\
\text { g/day }\end{array}$ & $\begin{array}{l}\text { High } \\
\text { g/day }\end{array}$ & $\mathrm{p}^{\mathrm{c}}$ & $\begin{array}{l}\text { Low } \\
\text { g/day }\end{array}$ & $\begin{array}{l}\text { High } \\
\text { g/day }\end{array}$ & $\mathrm{p}^{\mathrm{c}}$ \\
\hline Cooked or mashed potatoes & 88 & 126 & ns & 53 & 53 & ns \\
\hline Berries & 3 & 5 & $\mathrm{~ns}$ & 9 & 10 & ns \\
\hline Berry juices & 145 & 118 & ns & 79 & 78 & ns \\
\hline Fruit juices & 64 & 120 & $\mathrm{~ns}$ & 81 & 80 & ns \\
\hline Fruit & 84 & 162 & 0.0015 & 87 & 152 & 0.0001 \\
\hline Vegetable-based salads & 14 & 23 & 0.039 & 16 & 20 & ns \\
\hline Fresh vegetables and roots & 19 & 53 & 0.0002 & 31 & 56 & 0.0003 \\
\hline Vegetable dishes, cooked vegetables & s 16 & 48 & ns & 23 & 46 & 0.036 \\
\hline Salads including meat or fish & 7 & 5 & ns & 5 & 11 & ns \\
\hline Breakfast cereals, porridge & 50 & 81 & ns & 39 & 68 & 0.002 \\
\hline Pizza & 28 & 22 & ns & 19 & 16 & ns \\
\hline Rye bread & 116 & 120 & 0.032 & 56 & 57 & ns \\
\hline Wheat and white bread & 74 & 74 & ns & 55 & 60 & ns \\
\hline Wheat bun & 42 & 26 & ns & 25 & 19 & ns \\
\hline
\end{tabular}

\footnotetext{
a low consumption $=60$ times per month or less; high consumption=at least 60 times per month

${ }^{\mathrm{b}}$ Includes fresh and cooked vegetables, vegetable dishes, fruit and berries

${ }^{c}$ ns=non-significant (statistical test by mixed model of GLM)
}

regularly had lunch outside the home. Thus, an organized lunch seems to be an easy way to increase consumption of salad vegetables.

Associations between higher consumption of vegetables and having lunch outside the home might be explained by vegetables and fresh salads usually being included in the price of lunch in Finland. As a result, vegetables are often eaten at least with the midday meal. Alternatively, when lunch is prepared at home, vegetables frequently seem to be lacking. Not unexpectedly, however, eating in fast food restaurants was inversely associated with vegetable consumption. This does not take into account the small proportion of vegetables present in a hamburger. In agreement with our study, fruit and vegetable intake of American women has been shown to be lower among frequent fast food restaurant users, suggesting either healthy options being displaced by other foods in the restaurant, or abstention from choosing fruit and vegetables on other eating occasions (26).

Our finding of healthy lifestyle factors being associated with more frequent consumption of vegetables and fruit is in agreement with many recent studies. Physical activity has been shown to be an important factor in healthy lifestyle, especially in consumption of vegetables and berries $(15,18)$. Regular exercise and close attention to a healthful diet were associated with frequent vegetable consumption also in other studies carried out in Norway (4) and Spain (15). French students who believed in the importance of health behaviour also reported an effort to eat more fruit (19). In addition, smoking has previously been shown to be related to low vegetable consumption $(4,7,17)$.

The basic data for this study were collected by a questionnaire covering food frequencies, health behaviour and socioeconomic situation. Food frequencies are assumed to be representative of the habitual diet. Food intakes based on 24-h dietary recalls were also used in the analyses to estimate vegetable consumption. The value of the $24-\mathrm{h}$ recall is in providing estimates of the average intake of large groups that are comparable with those obtained using more cumbersome techniques (21). Under-reporting and intra-individual variation in food intake are the main sources of bias in the recollection of the previous day (22). Among young adults in our study, a high consumption frequencies of aggregated vegetables and fruit were shown to be associated with higher intakes of vegetable food items in the 24-h recall.

The participation rate was different between men $(58 \%)$ and women $(69 \%)$. This did not bias the results because sexes were analysed in separate models. Typically, subjects who refuse to participate are a heterogenous group, but those more interested in their diet in general tend to more willingly participate in dietary studies (23). Therefore, a difference exists between refusals and participants.

In our study, the participation rate also differed by education. The proportion of persons with high education was higher among women than men (Table 2). One assumption which might be made is that men with high education were not motivated or felt they were too busy to participate, whereas women with high education were more eager to participate in a health survey. The large proportion of women with high education may have biased the results. In addition, high educational level as well as female gender may predict under-reporting in daily food consumption (24). It is possible that the effect of background variables would have been stronger if the proportions of women with low education and men with high education had been higher, thus being more representative of the general population.

The Finnish National Nutrition Council (1) states that vegetables and fruit are to be eaten daily in many forms. For health promoters, the key is getting young adults, who are undergoing continual changes in their lives, to re-evaluate or reprioritize the need for vegetables and the benefit of more frequent vegetable and fruit consumption in their diet. Results of an earlier study suggest that the effectiveness of efforts to promote positive food behaviour among young adults may be improved by incorporating means to overcome common barriers (27). Lack of time, convenience and price were noted to have particularly large impacts on eating and food choices.

In conclusion, the challenge remains for nutrition specialists to determine an optimal way of motivating young adults to eat more vegetables and fruit. Factors such as recommending a midday meal containing vegetables should be considered as ways of increasing consumption of vegetables and fruit. 


\section{REFERENCES}

1. National Nutrition Council: Finnish Nutrition Recommendations. Committee report 1998:7. Helsinki: Ministry of Agriculture and Forestry;1999.

2. Becker W, Enghardt H: Utvecklingen av livsmedelskonsumtionen i Norden 1965-1990. En jämförelse baserad på per capita statistiken. Scand J Nutr 1993;37:118-24.

3. Roos G, Prättälä R and the FAIR-97-3096 Disparities Group (1999): Disparities in food habits. Review of research in 15 European countries. Helsinki: National Public Health Institute;1999.

4. Johansson L, Frost Andersen L: Who eats 5 a day?:Intake of fruit and vegetables among Norwegians in relation to gender and lifestyle. J Am Diet Assoc 1998;98:689-91.

5. Billson H, Pryer JA, Nichols R: Variation in fruit and vegetable consumption among adults in Britain. An analysis from the dietary and nutritional survey of British adults. Eur J Clin Nutr 1999;53:946-52.

6. Helakorpi S, Uutela A, Prättälä R, Puska P: Health behaviour and health among Finnish adult population, spring 1999.Helsinki: National Public Health Institute; 2000 .

7. Samuelson G, Bratteby L-E. Enghardt H, Hedgren M: Food habits and energy and nutrient intake in Swedish adolescents approaching the year 2000. Acta Pædiatr Suppl 1996;415:1-20.

8. Lau RR, Jacobs Quadrel M, Hartman KA: Development and change of young adults' preventive health beliefs and behaviour: influence from parents and peers. J Health Soc Behav 1990;31:240-59.

9. Holm L: Identity and dietary change. Scand J Nutr 1996;40 Suppl 31:95-8.

10. Valsta LM, Tapanainen H, Männistö S, Lahti-Koski M, Pietinen P: Differences in food consumption and nutritional quality of diet in Finland by age and education. Scand J Nutr 2000;44 Suppl 2:124.

11. FINDIET 1997 Study Group: The 1997 dietary survey of Finnish adults. Helsinki: National Public Health Institute;1998:B8.

12. Haraldsdottir J, Andersen L: Clustering of dietary variables. A study of young men and women. Scand J Nutr 1994;38:112-6.

13. Roos E. Prättälä R, Lahelma E, Kleemola P, Pietinen P: Modern and healthy?:Socioeconomic differences in the quality of diet. Eur J Clin Nutr 1996;50:753-60.

14. Georgiou C, Betts N, Hoerr SL, Keim K, Peters P, Stewart B, Voichick J: Among young adults, college students and graduates practiced more healthful habits and made more healthful food choices than did nonstudents. J Am Diet Assoc 1997;97:754-9.
15. Agudo A, Pera G, EPIC Group of Spain: Vegetable and fruit consumption associated with anthropometric, dietary and lifestyle factors in Spain. Public Health Nutr 1999;2:263-71.

16. De Irala-Estévez J, Groth $M$, Johansson L, Oltersdorf U, Prättälä R, Martínez-González MA: A Systematic review of socio-economic differences in food habits in Europe: consumption of fruit and vegetables. Eur J Clin Nutr 2000;54:706-14.

17. Birkett NJ: Intake of fruit and berries in smokers. Public Health Nutr 1999;2:217-22.

18. Cavadini C, Decarli B, Grin J, Narring F, Michaud P-A: Food habits and sport activity during adolescence:differences between athletic and nonathletic teenagers in Switzerland. Eur J Clin Nutr 2000;54 Suppl1:16-20.

19. Monneause MO, Bellisle F, Koppert G: Eating habits, food and health related attitudes and beliefs reported by French students. Eur J Clin Nutr 1997;51:46-53.

20. Vartiainen E, Jousilahti P, Alftan G, Sundvall J, Pietinen P, Puska P. Cardiovascular risk factor changes in Finland 1972-1997. Int J Epidemiol 2000;29:49-56.

21. Beaton GH, Milner J, Corey P, McGuire V, Cousins M, Stewart E, de Ramos M, Hewitt D, Grambsch PV, Kassim N, Little JA: Sources of variance in 24hour dietary recall data: implications for nutrition study design and interpretation. Am J Clin Nutr 1979;32:2546-59.

22. Jonnalagadda SS, Mitchell DC, Smiciklas-Wright $H$, Meaker KB, van Heel N Karmally W: Accuracy of energy intake data estimated by a multiple-pass, 24hour dietary recall technique. J Am Diet Assoc 2000;100:303-8,311.

23. Berglund L: Dietary investigations - what are the effects of invalid selection procedures and measurement errors? Scand J Nutr 1998;42:60-2.

24. Hirvonen T, Männistö S, Pietinen P. Increasing prevalence of underreporting does not necessarily destort dietary survyes. Eur J Clin Nutr 1997; 51:297-301

25. Kristal AR, Glanz K, Tilley BC, Li S: Mediating factors in dietary change: understanding the impact of a worksite nutrition intervention. Health Educ Behav 2000;27:112-25.

26. French SA, Harnack L, Jeffery RW: Fast food restaurant use among women in the Pound of Prevention Study: dietary, behavioral and demographic correlates. Int J Obes 2000;24:1353-59.

27. Betts NM, Amos RJ, Georgiou C, Hoerr SL, Ivaturi R, Keim KS, Tinsley A Voichick J: What young adults say about factors affecting their food intake. Ecol Food Nutr 1995;34:59-64. 